\title{
Letter to the Editors from Dr. B. A. GouLd, Director of the Cordoba Observatory, dated Cordoba, April 26, 1871. \\ [Concluded from page 80.]
}

The magnificence of the Milky Way in this vicinity is indescribable, surpassing the Pleiades or the Præsepe in richness, and exhibiting numerous huge clusters, the sight of which through the Tolles telescope evokes exclamations of astonishment and delight from every beholder, young or old, whether with or without astronomical information. Keen as was my desire for a photographic equipment before leaving home, it has been a hundred-fold increased since I began the survey of this most gorgeous of all the regions of the sky. Even yet I have not abandoned some hope that the friends of astronomy at home may be disposed to provide means for some permanent photographic record of these magnificent groups and splendid double stars. The transparency of the atmosphere would greatly reduce the needful time of exposure, and it gives peculiar opportunities for the success of the photographic method in other respects.

The news from the Eclipse-observers—so lorig and anxiously expected-is just beginning to arrive; our mail facilities having been sadly interfered with by the quarantine, established at Rosario, which has for more than two months placed an absolute interdiction upon all personal communication with Buenos Aires. From such accounts of the eclipse as have yet come to hand, it would seem that the results tend to confirm the doctrine that the corona is of a composite character, although this idea met with such opposition prior to the eclipse; but that my other observation, to which I attribute a good deal of importance, viz:- the change of outline in the more conspicuous and external portion of the phenomenon during the period of totality was neither verified ror the reverse, since the unfavorable atmospheric influences appear to have cut off this part of the exhibition at those few stations from which accounts have been received here. You may imagine with what eager interest we are awaiting the arrival of more detailed accounts from Europe or the United States.

You have unquestionably heard of the fearful pestilence which has been desolating the capital of this republic. The yellow fever, which broke out there at the close of January, has made such ravages that all commerce has 
been suspended, banks and public offices are closed, and not less than $\frac{8}{4}$ ths of the population have fled to the suburbs. The gates of the only practicable road to the interior of the country have been closed by the absolute interdiction of travel which the municipal authorities of Rosario have succeeded in imposing, notwithstanding the fever appears to have been purely local, and there is no authentic account of the disease being communicated in a single case at the distance of five miles from the center of the city. A few fatal cases have occurred where the patient left the city after contracting the infection, but the great majority in such cases have recovered. Within the city limits of Buenos Aires, the mortality has been terrific, reaching at one time a daily average of 500 in a population reduced, by the flight of all who could escape, to a number probably not much, if at all, exceeding 50,000.-The official reports give a total of more than 15,000 deaths from yellow fever since the middle of February up to which time the fatal cases were restricted to a single ward and seldom amounted to more than eight or ten a day. At first, too, the better classes escaped, but ultimately all classes were attacked indiscriminately, and in all parts of the city. The disease is at present on the wane quite rapidly, and the telegraph officials are returning to their posts, so that we are in daily receipt of more encouraging accounts.

Among the minor evils of this fearful epidemic have been the financial irregularities from which not only all government institutions, but likewise all commercial and social relations, have suffered. Even the Observatory has not escaped its share of these, although all public officers have done their best in its behalf, and have shown a most gratifying and encouraging interest. The citizens and authorities of Cordoba, too, have shown themselves desirous of aiding us on all occasions and in every way, and the Observatory has suffered decidedly less than other public institutions in this exceptional condition of affairs.

A scientific faculty is now organizing in this ancient university; and the professors of Chemistry, Botany, and Mineralogy have arrived from Germany and are already engaged in their respective researches. The flora of this region seems to be a characteristic one, but to contain a peculiarly small number of species. The professor of botany is making extensive collections, from which our own museums will doubtless profit in good time.

Before this reaches you, I trust that not only will the observatory have been completed by the erection of the portion which left the United States in January and i= probably at this very moment in the waters of the River Ia Plata, awaiting the reopening of the port of Buenos Aires, but also that our regular zone-work will have fairly begun. Still we have become inured to delays, and the vigorous prosecution of the Uranometry leaves no time to be consumed in lamentations.

If you know of any good man who has a few thousand dollars which he is disposed to contribute to the advancement of Astronomy, please tell lim that there are few if any ways in which they could be so effectively bestowed, as in securing photographs of the Southern sky at the present time. I have with me here the object glass with which $\mathrm{Mr}$. Rutherfurd took his magnificent photographs of the Moon, the Pleiades, the Præsepe and the cluster in Perseus, and am only in need of a mounting for the telescope, chemical equipments and a trained photographer, all of which a little money would enable us to secure without delay.-With these appliances, more astronomical material of the sort, to which the photographic method is specially adapted, could be collected in two years, than without it in twenty. And this material, once secured, can be elaborated at any subsequent time and the work repeated by any number of independent investigators. 